\title{
Microarray analysis reveals that high mobility group A1 is involved in colorectal cancer metastasis
}

\author{
YUSUKE TAKAHASHI $^{1,4}$, GENTA SAWADA ${ }^{1,4}$, TETSUYA SATO ${ }^{2}$, JUNJI KURASHIGE ${ }^{1}$, \\ KOSUKE MIMA ${ }^{1}$, TAE MATSUMURA ${ }^{1,4}$, RYUTARO UCHI ${ }^{1}$, HIROKI UEO ${ }^{1}$, MASAHISA ISHIBASHI ${ }^{1}$, \\ YUKI TAKANO $^{1}$, SAYURI AKIYOSHI ${ }^{1}$, HIDETOSHI EGUCHI ${ }^{1}$, TOMOYA SUDO ${ }^{1}$, KEISHI SUGIMACHI ${ }^{1}$, \\ JUN-ICHI TANAKA ${ }^{3}$, SHIN-EI KUDO ${ }^{3}$, YUICHIRO DOKI ${ }^{4}$, MASAKI MORI ${ }^{4}$ and KOSHI MIMORI ${ }^{1}$ \\ ${ }^{1}$ Department of Surgery, Kyushu University Beppu Hospital, Beppu; ${ }^{2}$ Division of Bioinformatics, Medical Institute \\ of Bioregulation, Kyushu University, Fukuoka; ${ }^{3}$ Digestive Disease Center, Showa University \\ Northern Yokohama Hospital, Yokohama; ${ }^{4}$ Department of Gastroenterological Surgery, \\ Osaka University, Graduate School of Medicine, Suita, Japan
}

Received March 11,2013; Accepted April 23, 2013

DOI: $10.3892 /$ or.2013.2602

\begin{abstract}
Tumor size indicates the extent of cell proliferation in most cases of colorectal cancer (CRC), although there are some advanced small tumors with metastases. Lymph node metastasis is a significant factor that greatly impacts disease prognosis in CRC cases. The underlying factors that cause lymph node metastasis in CRC cells are not fully understood. We investigated the mechanism that might induce CRC metastasis by focusing on smaller sized $(<2 \mathrm{~cm})$ invasive tumors. We carried out gene expression array analysis for CRC cases; group 1 consisted of 6 cases with tumors $<2 \mathrm{~cm}$ with metastases, and group 2 consisted of 65 cases with tumors $>2 \mathrm{~cm}$ without metastases. Results were validated using gene expression array data from an additional 77 cases and another bulk case set of 172 cases. Gene Ontology and pathway analysis using microarray data revealed that anti-apoptotic activity had a crucial role in CRC metastasis. High mobility group A1 (HMGAl) was identified as a biomarker for poor prognosis and metastasis formation. HMGAl expression levels were higher in lymph node-positive cases than in lymph node-negative cases, even in subgroup analysis of submucosal invasive cases. The present study strongly supports the clinical significance of $H M G A l$ expression as a predictive indicator of lymph node metastasis in CRC cases, even in submucosal invasive cases which could be cured by local resection.
\end{abstract}

Correspondence to: Professor Koshi Mimori, Department of Surgery, Kyushu University Beppu Hospital, 4546 Tsurumihara, Beppu, Oita 874-0838, Japan

E-mail:kmimori@beppu.kyushu-u.ac.jp

Key words: colorectal cancer, lymph node metastasis, HMGA1, submucosal invasive cancer, tumor size

\section{Introduction}

Although tumor size is not a factor in deciding tumor stage according to TNM classification of the UICC (Union for International Cancer Control) or the Japanese classification of colorectal carcinoma, tumor size is generally considered to be an indicator of proliferation potency and thereby malignancy. There are some colorectal cancer (CRC) cases with small tumors and metastasis, and, conversely, tumors of large size without metastasis. Such small tumors with the capability to metastasize are estimated to have a tendency of vertical invasion and vascular invasion, and these tumors often have a high malignancy grade that induces lymph node or distant metastasis. Therefore, we hypothesized that such small but advanced cancer might have distinctive characteristics which are involved in cancer metastasis, particularly for the lymph nodes.

Several researchers have studied metastasis-regulating factors (1-3). Gene expression arrays using in vivo models (2) and clinical samples $(1,2)$ and proteomics analysis using clinical samples (3) have all been carried out, and certain genes and pathways have been identified as biomarkers for CRC metastasis. There is some discord between past reports, however, therefore the underlying factors that cause tumor metastasis remain to be fully understood.

Lymph node metastasis is a significant factor that has an impact on disease prognosis in CRC cases. While patients without metastasis can mostly be cured by resection of the primary tumor and thus have a 5-year survival rate exceeding $80 \%$, patients with lymph node metastasis often experience a relapse and therefore have a 5 -year survival rate of $<50 \%(4,5)$. We have, thus, focused on identifying biomarkers for CRC lymph node metastasis, which will be helpful in determining treatment strategy and may provide further insight into tumor biology.

In the present study, we investigated significant factors for cancer metastasis, particularly lymph node metastasis, by using gene expression microarray analysis of small tumors with metastases and large tumors without metastases. 


\section{Materials and methods}

Patients and sample collection. We used a total of 320 CRC samples, in which 148 were used as pure cancer tissues separated by laser microdissection ( 71 cases for set 1 and all 148 cases for set 2) and 172 were used in bulk (set 3). All samples were obtained during surgery. All patients underwent resection of the primary tumor at Kyushu University Hospital at Beppu and affiliated hospitals between 1992 and 2007. Written informed consent was obtained from all patients. All patients had a clear histological diagnosis of CRC and were closely followed up every 3 months. The follow-up period in set 1 ranged from 0.1 to 12.3 years, with a mean of 3.8 years; follow up in set 2 ranged from 0.1 months to 3.2 years with a mean of 2.1 years. Resected cancer tissues were immediately cut and stored in RNAlater (Ambion) or embedded in Tissue-Tek OCT (optimum cutting temperature) medium (Sakura, Tokyo, Japan), frozen in liquid nitrogen, and kept at $-80^{\circ} \mathrm{C}$ until RNA extraction. Frozen tissue specimens were homogenized in guanidinium thiocyanate, and total RNA was obtained by ultracentrifugation through a cesium chloride cushion. cDNA for reverse-transcription PCR was synthesized from $8.0 \mu \mathrm{g}$ of total RNA with M-MLV Reverse Transcriptase (Invitrogen, Carlsbad, CA, USA). Clinicopathological factors and clinical stage were classified using the TNM system of classification. All sample data, including age, gender, histology, tumor depth, lymph node metastasis, lymphatic invasion, vascular invasion, liver metastasis and postoperative liver recurrence, were obtained from the clinical and pathological records.

Laser microdissection. Tissue samples were microdissected using the LMD6000 Laser microdissection system (Leica Laser Microdissection System; Leica Microsystems, Wetzlar, Germany) as previously described (6). For laser microdissection, five micron frozen sections were fixed in $70 \%$ ethanol for $30 \mathrm{sec}$, stained with hematoxylin and eosin, and dehydrated for 5 sec each in 70, 95 and 100\% ethanol. Sections were air-dried, then microdissected with the LMD system. Target cells were excised, at least 100 cells per section, and bound to the transfer film. Then, total RNA was extracted.

Gene expression microarray. We used the commercially available Human Whole Genome Oligo DNA Microarray kit (Agilent Technologies, Santa Clara, CA, USA). A list of genes on this cDNA microarray is available at http://www.chem. agilent.com $/$ scripts/generic.asp?lpage $=5175 \&$ amp; indcol $=Y \&$ amp;prodcol=Y\&prodcol=N\&indcol=Y\&prodcol=N. Cyanine (Cy)-labeled cRNA was prepared using T7 linear amplification as described in the Agilent Low RNA Input Fluorescent Linear Amplification kit manual (Agilent Technologies). Labeled cRNA was fragmented and hybridized to an oligonucleotide microarray (Whole Human Genome 4x44K Agilent G4112F). Fluorescence intensities were determined with an Agilent DNA Microarray Scanner and were analyzed using G2567AA Feature Extraction software version A.7.5.1 (Agilent Technologies), which used the LOWESS (locally weighted linear regression curve fit) normalization method (7). This microarray study followed MIAME guidelines issued by the Microarray Gene Expression Data group (8).
Table I. Clinicopathological factors in colorectal cancer cases of group 1 and group 2 .

\begin{tabular}{|c|c|c|}
\hline & $\begin{array}{c}\text { Group } 1 \\
(\mathrm{~N}=6)\end{array}$ & $\begin{array}{c}\text { Group } 2 \\
(\mathrm{~N}=65)\end{array}$ \\
\hline Factors & $\mathrm{n}, \%$ & $\mathrm{n}, \%$ \\
\hline Age (years) & $57.5 \pm 10.8$ & $67.0 \pm 11.0$ \\
\hline \multicolumn{3}{|l|}{ Gender } \\
\hline Male & $3(50.0)$ & $38(58.0)$ \\
\hline Female & $3(50.0)$ & $27(42.0)$ \\
\hline Tumor size $(\mathrm{mm})$ & $19 \pm 2$ & $49 \pm 19$ \\
\hline \multicolumn{3}{|l|}{ Histological grade } \\
\hline Well & $1(16.7)$ & $44(67.7)$ \\
\hline Moderate & $5(83.3)$ & $21(32.3)$ \\
\hline \multicolumn{3}{|l|}{ Depth } \\
\hline $\mathrm{M}$ & & $1(1.5)$ \\
\hline SM & & $5(7.7)$ \\
\hline MP & $1(16.7)$ & $14(21.5)$ \\
\hline $\mathrm{SS}, \mathrm{SE}$ & $5(83.3)$ & $41(63.1)$ \\
\hline SI & & $4(6.2)$ \\
\hline \multicolumn{3}{|c|}{ Lymph node metastasis } \\
\hline Present & $6(100.0)$ & $0(0.0)$ \\
\hline Absent & $0(0.0)$ & $65(100.0)$ \\
\hline \multicolumn{3}{|c|}{ Lymphatic invasion } \\
\hline Present & $6(100.0)$ & $36(55.4)$ \\
\hline Absent & $0(0.0)$ & $29(44.6)$ \\
\hline \multicolumn{3}{|l|}{ Venous invasion } \\
\hline Present & $5(83.3)$ & $31(47.7)$ \\
\hline Absent & $1(16.7)$ & $34(52.0)$ \\
\hline \multicolumn{3}{|l|}{ Liver metastasis } \\
\hline Present & $1(16.7)$ & $0(0.0)$ \\
\hline Absent & $5(83.3)$ & $65(100.0)$ \\
\hline \multicolumn{3}{|c|}{ Peritoneal dissemination } \\
\hline Present & $0(0.0)$ & $0(0.0)$ \\
\hline Absent & $6(100.0)$ & $65(100.0)$ \\
\hline \multicolumn{3}{|l|}{ Distant metastasis } \\
\hline Present & $0(0.0)$ & $0(0.0)$ \\
\hline Absent & $6(100.0)$ & $65(100.0)$ \\
\hline
\end{tabular}

Well, well differentiated tubular adenocarcinoma; Moderate, moderately differentiated tubular adenocarcinoma; M, mucosa; SM, submucosa; MP, muscularis propria; SE, serosa exposed; SS, subserosa; SI, serosa infiltrating.

Gene Ontology analysis. All 1662 genes which were significantly differentially expressed between the two groups were further analyzed using the Gene Ontology database (http:// www.geneontology.org/).

Pathway analysis. Genesets and pathways mentioned in the Molecular Signatures Database (http://www.broadinstitute. org/gsea/msigdb/index.jsp), Kyoto Encyclopedia of Genes and Genomes (http://www.genome.jp/kegg/), SABioscience pathway central (http://www.sabiosciences.com/pathway- 
Table II. Significantly different Gene Ontology (GO) in 1662 significant genes.

\begin{tabular}{llll}
\hline Category & GO ID & & Name \\
\hline Molecular function & GO:0005515 & Protein binding & $1.58 \mathrm{E}-08$ \\
& GO:0019901 & Protein kinase binding & 0.00892753 \\
& GO:0019899 & Enzyme binding & 0.00489524 \\
& GO:0005096 & GTPase activator activity & 0.00288377 \\
& GO:0004843 & Ubiquitin-specific protease activity & 0.00878492 \\
& GO:0003899 & DNA-directed RNA polymerase activity & 0.00575996 \\
& GO:0051059 & NF-kB binding & 0.00691413 \\
Biological process & GO:0006915 & Apoptotic process & 0.00842709 \\
& GO:0006468 & Protein phosphorylation & 0.00921 \\
& GO:0009615 & Response to virus & 0.00453601 \\
& GO:0006974 & Response to DNA damage stimulus & 0.00822752 \\
& GO:0006368 & Transcription elongation from RNA polymerase II promoter & 0.00160609 \\
& GO:0043547 & Positive regulation of GTPase activity & 0.00107171 \\
& GO:0042384 & Cilium assembly & 0.00586548 \\
& GO:0050434 & Positive regulation of viral transcription & 0.00386628 \\
& GO:0021987 & Cerebral cortex development & 0.00424518 \\
& GO:0043407 & Negative regulation of MAP kinase activity & 0.00318089 \\
& GO:0006446 & Regulation of translational initiation & 0.00468904 \\
& GO:0006884 & Cell volume homeostasis & 0.00686783 \\
& GO:0042058 & Regulation of epidermal growth factor receptor signaling pathway & 0.00861317 \\
& GO:0005829 & Cytosol & 0.00019253 \\
& GO:0005730 & Nucleolus & 0.00011503 \\
& GO:0005654 & Nucleoplasm & 0.00130461 \\
& GO:0005794 & Golgi apparatus & 0.00767627 \\
& GO:0005856 & Cytoskeleton & 0.00269772 \\
& GO:0043234 & Protein complex & 0.00182768 \\
& GO:0000242 & Pericentriolar material & 0.00386903 \\
\hline
\end{tabular}

central.php) and Reactome (http://www.reactome.org/ ReactomeGWT/entrypoint.html) were corrected and analyzed with the EEM (Extraction of Expression Modules) method (9).

Quantitative real-time reverse transcription-PCR. For quantitative real-time reverse transcription (qRT)-PCR, high mobility group A1 (HMGA1) (NM_145903.2, NM_002131.3, NM_145902.2, NM_145905.2, NM_145899.2, NM_145901.2) primersequences were 5'-GAAAAGGACGGCACTGAGAA-3' and 5'-CTCTTAGGTGTTGGCACTTCG-3'. To normalize for RNA concentration, glyceraldehyde-3-phosphate dehydrogenase (GAPDH) served as an internal control. The sequences of the GAPDH primers were: sense, 5'-TTGGTATCG TGGAAGGACTCA-3' and antisense, 5'-TGTCATCATATT TGGCAGGTT-3'. The amplification protocol included an initial denaturation step at $95^{\circ} \mathrm{C}$ for $10 \mathrm{~min}$, followed by 45 cycles of $95^{\circ} \mathrm{C}$ for $10 \mathrm{sec}$ and $60^{\circ} \mathrm{C}$ for $30 \mathrm{sec}$. qRT-PCR was performed in a LightCycler 480 instrument (Roche Applied Science, Basel, Switzerland) using the LightCycler 480 Probes Master kit (Roche Applied Science). All concentrations were calculated relative to the concentration of cDNA using Human Universal Reference Total RNA (Clontech, Palo Alto, CA, USA). The concentration of HMGA1 was then divided by the concentration of the endogenous reference (GAPDH) to obtain normalized expression values.
Statistical analysis. For gene expression array analysis, the differences between groups were estimated using the Student's t-test after expression signals were calculated by log2-transformation of the normalized data. Differentially expressed genes were detected by using the P-value, fold-change value and q-value. All differences were considered statistically significant at the level of $\mathrm{P}<0.05$ or false discovery rate (FDR) $\mathrm{P}<0.05$. Data from RT-PCR analyses were analyzed using JMP 5 software (JMP, Cary, NC, USA). Overall survival rates were calculated actuarially according to the Kaplan-Meier method and were measured from the day of surgery. Differences between groups were estimated using the Chi-square test, Student's t-test, repeated-measures ANOVA and log-rank test. A probability level of 0.05 was selected for statistical significance.

\section{Results}

A total of 1662 genes are differently expressed between the two groups. We first selected 71 cases (set 1) and subdivided them into two groups. Group 1 consisted of 6 colorectal cancers which were $<2 \mathrm{~cm}$ in size and had metastasis; group 2 consisted of 65 cases with tumors $>2 \mathrm{~cm}$ in size that lacked metastasis (Table I). A significant difference in expression level (FDR <0.05) between the two groups was found in 
Table III. Pathways differently activated between two groups.

\begin{tabular}{lccc}
\hline & \multicolumn{2}{c}{ Average score } & \\
\cline { 2 - 3 } Gene set & Group 1 & Group 2 & P-value \\
\hline HOLLMAN_APOPTOSIS_VIA_CD40_UP & -0.849748231 & 0.472445257 & 0.001910051 \\
LAU_APOPTOSIS_CDKN2A_UP & -0.833935125 & 1.308750297 & 0.004621955 \\
KEGG_PHOSPHATIDYLINOSITOL_SIGNALING_SYSTEM & -0.662010266 & -0.386950146 & 0.007638363 \\
KEGG_WNT_SIGNALING_PATHWAY & -0.735968923 & -0.413898949 & 0.010503868 \\
TIAN_TNF_SIGNALING_VIA_NFKB & -0.584241501 & 0.67357094 & 0.026420951 \\
BREDEMEYER_RAG_SIGNALING_VIA_ATM_NOT_VIA_NFKB_UP & -0.777042962 & 0.118487532 & 0.032926144 \\
WONG_EMBRYONIC_STEM_CELL_CORE & 0.402726415 & -0.179854864 & 0.039863172 \\
Apoptosis & -0.55085111 & -0.263926672 & 0.046064516 \\
\hline
\end{tabular}
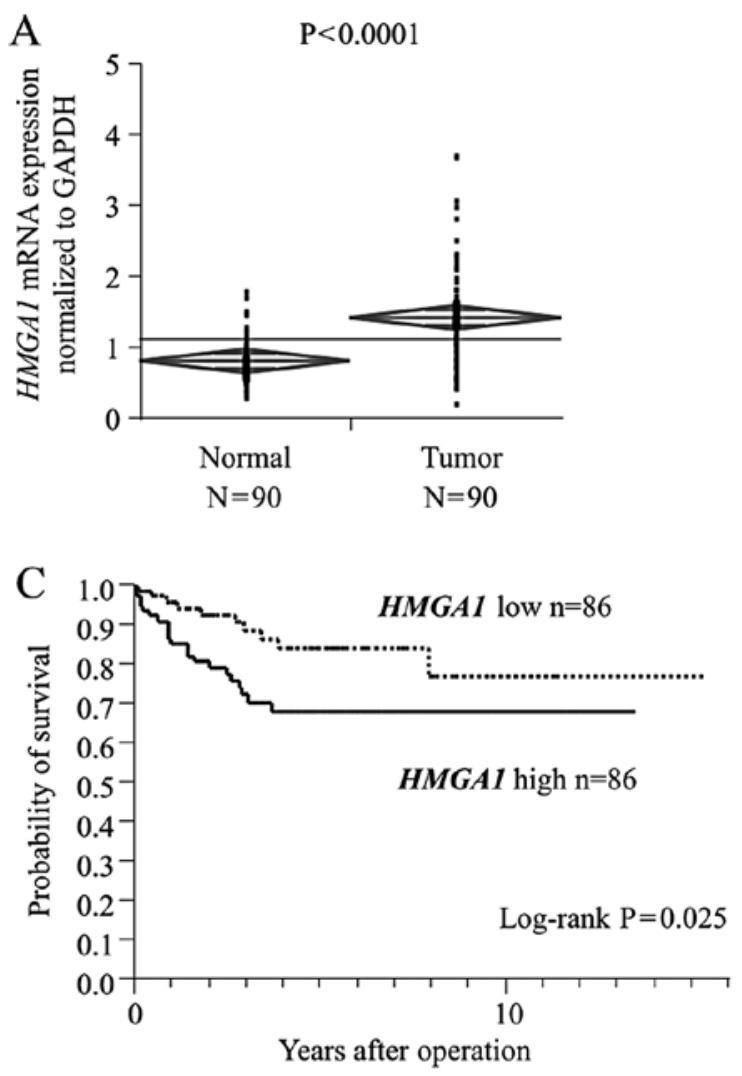

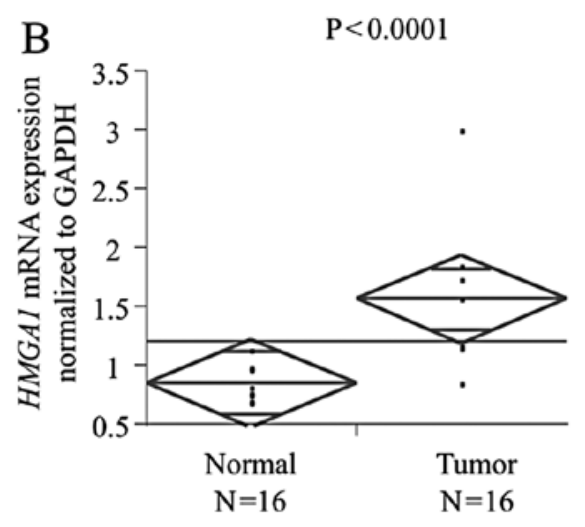

$\mathrm{D}$

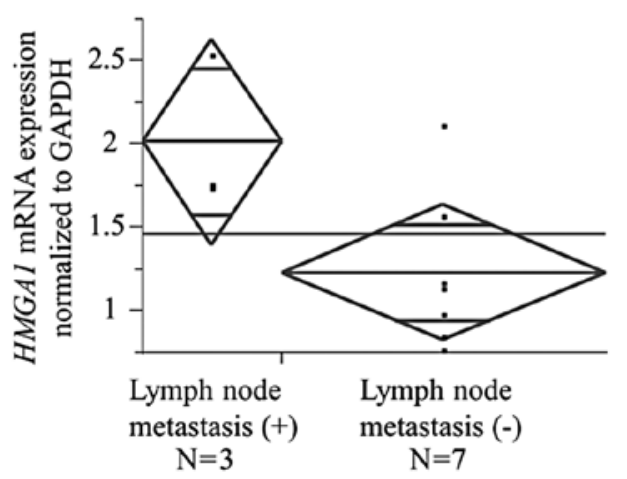

Figure 1. HMGA1 mRNA expression level is a predictive indicator of prognosis and lymph node metastases in CRC cases. (A) Analysis of $H M G A 1$ mRNA expression in colorectal tumor tissues (tumor) and corresponding normal mucosa (normal) by real-time RT-PCR for 90 CRC cases. HMGA1 mRNA was significantly upregulated in tumor tissues compared with normal mucosa $(\mathrm{P}<0.0001)$. (B) Analysis of $H M G A 1$ mRNA expression in colorectal tumor tissues (tumor) and corresponding normal mucosa (normal) by real-time RT-PCR for 16 CRC cases with smaller tumor size ( $<20$ mm). HMGA1 mRNA was significantly upregulated in tumor tissues compared with normal mucosa $(\mathrm{P}<0.0001)$, even in cases with smaller tumor size. (C) Kaplan-Meier analysis of overall survival for 172 patients with CRC according to $H M G A 1$ mRNA expression. (D) Analysis of HMGA1 mRNA expression in colorectal tumor tissues for 10 submucosal invasive cases. HMGA1 mRNA was significantly higher in tumor tissues with lymph node metastasis than in cases without lymph node metastasis $(\mathrm{P}=0.0413)$. Lymph node metastasis $(+)$, lymph node metastasis positive; lymph node metastasis $(-)$, lymph node metastasis negative.

62 genes and $\mathrm{P}<0.05$ was observed in 1662 genes (data not shown). These included some well described genes, such as the angiogenesis factor hypoxia inducible factor 1 (HIF1A); cell cycle regulators such as CDC34 and CD20; snail homolog 1 (SNAI1), which is involved in the epithelial to mesenchymal transition (EMT); the NF- $\mathrm{B}$ pathway gene nuclear factor of $\kappa$ light polypeptide gene enhancer in B-cells inhibitor
(NFKBI); the oncogenic pathway gene RAS protein activator like 1 (RASAL1); and the colon cancer stem cell relating gene leucine-rich repeat containing $\mathrm{G}$ protein-coupled receptor 5 (LGR5).

Anti-apoptotic activity induces metastasis formation. We performed Gene Ontology analysis to annotate the 1662 genes 


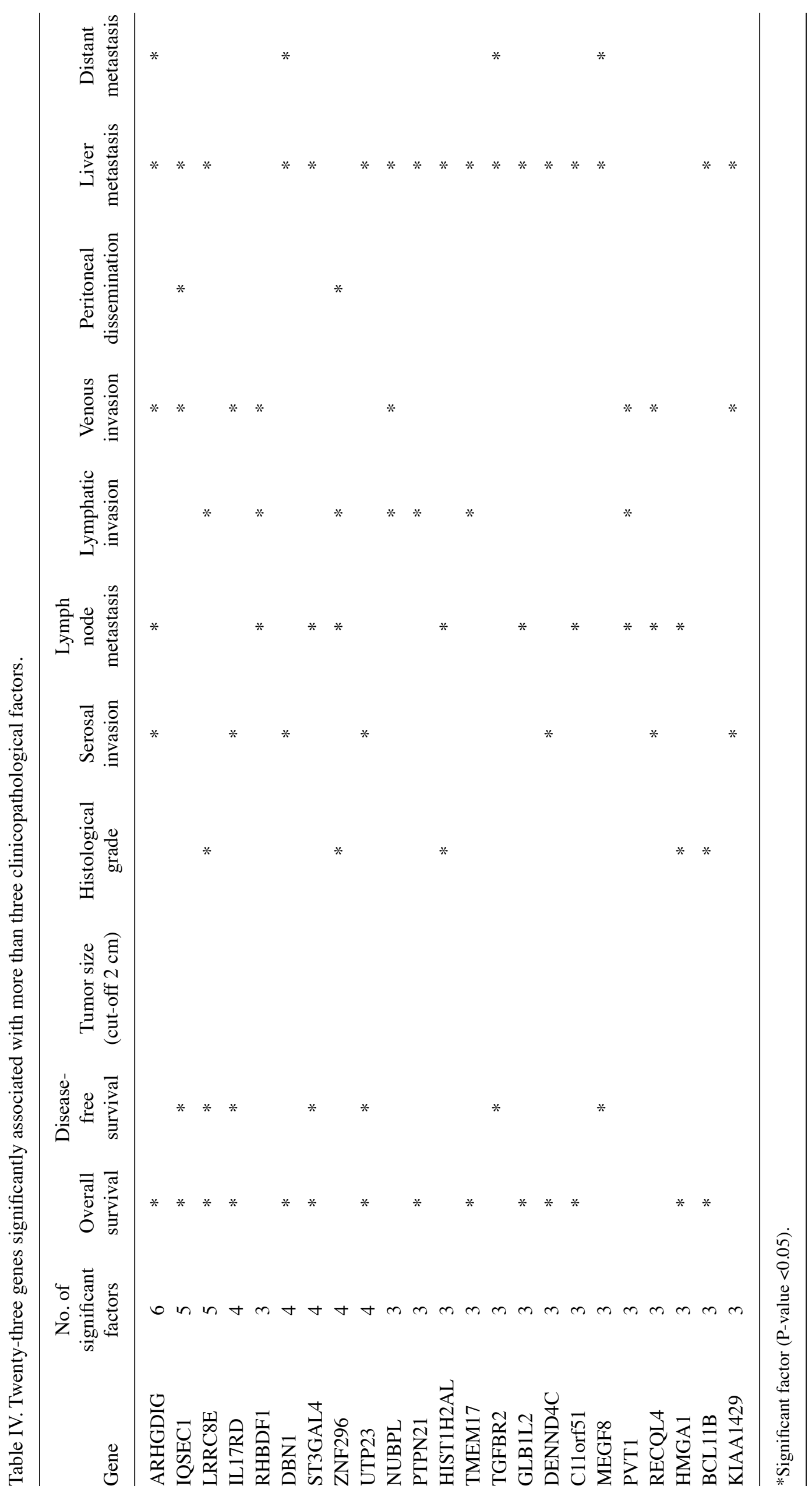


which were significantly differently regulated in group 1 . Results are shown in Table II. The Gene Ontologies 'NF-кB binding', 'negative regulation of MAP kinase activity', 'regulation of epidermal growth factor receptor signaling pathway' and 'apoptotic process' were significantly enriched in this set of genes.

We performed pathway analysis to identify the pathways which actually determine the character of these tumors. A summary result of the analysis is shown in Table III. No significant difference of activation level was found in pathways associated with oncogenes such as RAS and cell-cycle genes. However, we identified significant inactivation of genes involved in the WNT signaling pathway and several apoptosis-related pathways in group 1. Inactivation of WNT signaling seemed to be associated with the smaller tumor size of group 1. The inactivation of apoptosis in group 1 tumors may contribute to their ability to form metastasis sites.

We also carried out gene expression array for 77 more cases for further analysis. Using the microarray results for all 148 CRC cases, we investigated the correlation of the above 1662 genes with prognosis and the following clinicopathological factors: overall survival, disease-free survival, tumor size, histological grade, serosal invasion, lymph node metastasis, lymphatic invasion, venous invasion, peritoneal dissemination, liver metastasis and distant metastasis. Twenty-three genes, whose count of significant factors was over three, were extracted (Table IV). We focused on HMGAl as it is reported to have a critical role in both neoplastic transformation and the inactivation of p53's apoptotic function (10). HMGAl had an FDR $<0.05$ in the analysis described above for the 1662 identified genes (data not shown).

HMGA1 mRNA expression is a robust indicator of lymph node metastasis and patient prognosis. HMGA1 mRNA expression in the bulk 172 tumor tissues and corresponding normal tissues (case set 3) was examined by qRT-PCR to validate the clinical significance of HMGAl expression in CRC cases. HMGAI mRNA levels in cancerous tissues were significantly higher than those in non-cancerous tissues $(\mathrm{P}<0.0001$; Fig. $1 \mathrm{~A})$. The significant difference was maintained in the analysis of small sized tumors ( $<2 \mathrm{~cm}, \mathrm{P}<0.0001$; Fig. 1B).

Next, we divided the 172 patients with CRC into a high $H M G A l$ expression group $(\mathrm{n}=86)$ and a low $H M G A l$ expression group ( $\mathrm{n}=86)$, classified as having expression levels higher or lower than the median value, respectively. Clinicopathological factors were compared between the high and low HMGAI mRNA expression groups (Table V). The high HMGAl expression group showed higher risk for lymph node metastasis. Univariate analysis of lymph node metastasis revealed that the relative level of $H M G A 1$ expression was a lymph node metastasis risk factor similar to serosal invasion, lymphatic invasion, venous invasion and liver metastasis (Table VI). Variables with a value of $\mathrm{P}<0.05$ were selected for multivariate analysis. Multivariate analysis showed that $H M G A l$ expression was an independent lymph node metastasis risk factor in patients with CRC (relative risk, 3.46; $\mathrm{P}=0.001$; Table VI). With regard to overall survival, patients with high $H M G A 1$ expression had a significantly poorer prognosis than those with low HMGAI expression ( $\mathrm{P}=0.0046$; Fig. 1C). Furthermore, we performed subgroup analysis for submucosal invasive cancer, which
Table V. HMGAl mRNA expression and clinicopathological factors in 172 cases of colorectal cancer.

\begin{tabular}{|c|c|c|c|}
\hline & $\begin{array}{c}\text { Low } \\
\text { expression } \\
(\mathrm{N}=86) \\
\end{array}$ & $\begin{array}{c}\text { High } \\
\text { expression } \\
(\mathrm{N}=86) \\
\end{array}$ & \\
\hline Factors & $\mathrm{n}, \%$ & $\mathrm{n}, \%$ & P-value \\
\hline \multicolumn{4}{|l|}{ Age (years) } \\
\hline$<65$ & $25(29.07)$ & $35(40.70)$ & 0.109 \\
\hline$\geq 66$ & $61(70.93)$ & $51(59.30)$ & \\
\hline \multicolumn{4}{|l|}{ Gender } \\
\hline Male & $52(60.47)$ & $51(59.30)$ & 0.8761 \\
\hline Female & $34(39.53)$ & $35(40.70)$ & \\
\hline \multicolumn{4}{|c|}{ Histological grade } \\
\hline Well/moderate & $80(93.02)$ & $80(93.02)$ & 1 \\
\hline Other & $6(6.98)$ & $6(6.98)$ & \\
\hline \multicolumn{4}{|l|}{ Tumor size (mm) } \\
\hline$\leq 20$ & $4(4.65)$ & $11(12.79)$ & 0.0505 \\
\hline$>20$ & $78(90.70)$ & $70(81.40)$ & \\
\hline \multicolumn{4}{|l|}{ Serosal invasion } \\
\hline Absent & $27(31.40)$ & $23(26.74)$ & 0.5016 \\
\hline Present & $59(68.60)$ & $63(73.26)$ & \\
\hline \multicolumn{4}{|c|}{ Lymph node metastasis } \\
\hline No & $57(66.28)$ & $34(39.53)$ & $0.0003^{\mathrm{a}}$ \\
\hline $\mathrm{N} 1-2$ & $28(32.56)$ & $52(60.47)$ & \\
\hline \multicolumn{4}{|c|}{ Lymphatic invasion } \\
\hline Absent & $56(65.12)$ & $44(51.16)$ & 0.076 \\
\hline Present & $30(34.88)$ & $41(47.67)$ & \\
\hline \multicolumn{4}{|l|}{ Venous invasion } \\
\hline Absent & $70(81.40)$ & $64(74.42)$ & 0.3321 \\
\hline Present & $16(18.60)$ & $21(24.42)$ & \\
\hline \multicolumn{4}{|l|}{ Liver metastasis } \\
\hline Absent & $79(91.86)$ & $75(87.21)$ & 0.3172 \\
\hline Present & $7(8.14)$ & $11(12.79)$ & \\
\hline \multicolumn{4}{|c|}{ Peritoneal dissemination } \\
\hline Absent & $84(97.67)$ & $80(93.02)$ & 0.1389 \\
\hline Present & $2(2.33)$ & $6(6.98)$ & \\
\hline \multicolumn{4}{|c|}{ Distant metastasis } \\
\hline Absent & $84(97.67)$ & $84(97.67)$ & 1 \\
\hline Present & $2(2.33)$ & $2(2.33)$ & \\
\hline \multicolumn{4}{|l|}{ UICC stage } \\
\hline $0, \mathrm{I}, \mathrm{II}$ & $54(62.79)$ & $34(39.53)$ & $0.0022^{\mathrm{a}}$ \\
\hline III, IV & $32(37.21)$ & $52(60.47)$ & \\
\hline
\end{tabular}

aStatistically significant; well, well differentiated tubular adenocarcinoma; moderate, moderately differentiated tubular adenocarcinoma; UICC, Union for International Cancer Control.

can be removed completely by local resection if lymph node metastases do not exist. Lymph node metastasis was observed in 3 out of 10 submucosal invasive cancer cases, and 3 cases with lymph node metastasis had significantly higher HMGAl mRNA expression than the other 7 cases without lymph node metastasis $(\mathrm{P}=0.0413$; Fig. 1D). 
Table VI. Univariate and multivariate analysis for lymph node metastasis (logistic regression model).

\begin{tabular}{|c|c|c|c|c|c|c|}
\hline \multirow[b]{2}{*}{ Factors } & \multicolumn{3}{|c|}{ Univariate analysis } & \multicolumn{3}{|c|}{ Multivariate analysis } \\
\hline & $\mathrm{RR}$ & $95 \% \mathrm{CI}$ & P-value & $\mathrm{RR}$ & $95 \% \mathrm{CI}$ & $\mathrm{P}$-value \\
\hline $\begin{array}{l}\text { Age (years) } \\
(<65 / \geq 66)\end{array}$ & 0.39 & $0.204-0.744$ & 0.0046 & - & - & - \\
\hline $\begin{array}{l}\text { Gender } \\
\text { (male/female) }\end{array}$ & 0.92 & $0.498-1.706$ & 0.7991 & - & - & - \\
\hline $\begin{array}{l}\text { Serosal invasion } \\
\text { (absent/present) }\end{array}$ & 5.25 & $2.481-12.007$ & $<0.0001^{\mathrm{a}}$ & 2.80 & $1.177-7.040$ & $0.023^{\mathrm{a}}$ \\
\hline $\begin{array}{l}\text { Lymphatic invasion } \\
\text { (absent/present) }\end{array}$ & 5.48 & $2.852-10.843$ & $<0.0001^{\mathrm{a}}$ & 2.83 & $0.297-6.253$ & $0.009^{\mathrm{a}}$ \\
\hline $\begin{array}{l}\text { Venous invasion } \\
\text { (absent/present) }\end{array}$ & 5.83 & $2.575-14.578$ & $<0.0001^{\mathrm{a}}$ & 2.68 & $0.993-7.697$ & 0.057 \\
\hline $\begin{array}{l}\text { Liver metastasis } \\
\text { (absent/present) }\end{array}$ & 0.55 & $3.024-71.924$ & $0.0017^{\mathrm{a}}$ & 7.00 & $1.503-52.834$ & $0.026^{\mathrm{a}}$ \\
\hline $\begin{array}{l}H M G A 1 \text { mRNA expression } \\
\text { (low/high) }\end{array}$ & 3.11 & $1.679-5.882$ & $0.0004^{\mathrm{a}}$ & 3.46 & $1.676-7.832$ & $0.001^{\mathrm{a}}$ \\
\hline
\end{tabular}

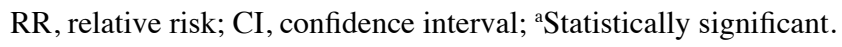

\section{Discussion}

In the present study, we focused on colorectal cancer (CRC) with metastasis in spite of small size $(<2 \mathrm{~cm})$. These cancer cells seem to have a greater ability for invasion and migration. Therefore, we comprehensively analyzed the gene expression profile of these cancer tissues to identify the genes or pathways which regulate the cancer metastasis.

Biomarkers for CRC lymph node metastasis have been reported as follows; Grade et al (1) carried out gene expression array analysis on 73 colon cancer tissues and comparative genomic hybridization (CGH) for 32 tumors. They identified 68 genes that were significantly differentially expressed between lymph node-negative and lymph node-positive tumors, the functional annotation of which revealed a preponderance of genes that play a role in cellular immune response and surveillance. Using an in vivo orthotopic CRC model and clinical samples, Hao et al (2) discovered that a five-gene signature [v-yes-1 Yamaguchi sarcoma viral related oncogene homolog (LYN), syndecan binding protein (SDCBP), mitogen-activated protein kinase kinase kinase kinase 4 (MAP4K4), dickkopf 1 homolog $(D K K 1)$, and midline 1 (MIDI)] was closely correlated with lymph node metastasis in CRC. Using proteomics analysis, Meding et al (3) revealed that expression levels of FXYD domain containing ion transport regulator 3 (FXYD3), S100 calcium binding protein A11 (S100A11), and glutathione S-transferase mu 3 (GSTM3) are novel markers for regional lymph node metastasis in colon cancer. In addition, specific signatures associated with tumor stage and lymph node metastases were described $(11,12)$.

In the present study, the FXYD5 and S100A genes were significantly regulated in group 1; however, we did not find most of the previously described markers. In the present study, we identified lymph node metastasis-related genes, particularly in small tumors $(<20 \mathrm{~mm})$, since we considered that they would be the most informative for clinical applications. This might explain the discrepancy between our results and past reports.

As for the characteristics of the identified genes, we found that anti-apoptotic activity played a key role in cancer metastasis. In general, deregulated cell proliferation together with suppressed apoptosis constitute the minimal common platform upon which tumorigenesis is based (13). The initial population of malignant cells avoids the apoptotic pathway and then continues to rampantly proliferate. Anti-apoptotic activity must, therefore, be required for cancer cells to form metastases. Notably, genes regulating the epithelial-to-mesenchymal transition related pathways, which have been considered to promote cancer cell invasion and migration $(14,15)$, and those regulating cancer stem cell related pathways, which have the potential to initiate and sustain tumor growth and metastasis $(16,17)$, did not affect metastatic ability in our study.

We showed that HMGAl expression has a significant correlation with lymph node metastasis in CRC cases. The high-mobility group (HMG) proteins are low-molecular weight nuclear factors with non-histone chromosomal accessory functions (18). The A subgroup of HMG interacts with the minor groove of numerous AT-rich promoters and enhancers (19) and plays key roles in chromatin architecture and gene transcription control $(19,20)$. Under physiological conditions, HMGA protein expression is high during embryogenesis $(21,22)$ and decreases to low to undetectable levels in adult tissues. High $H M G A$ expression in adult life is associated only with pathological conditions such as human carcinomas of the thyroid $(23,24)$, colon $(25-27)$, prostate (28), pancreas (29), cervix (30), ovary (31) and breast (32). Moreover, large scale gene expression studies show that high expression portends a poor prognosis in some tumors $(33,34)$. HMGA1 is also enriched in embryonic stem cells and high grade (poorly 
differentiated) cancer, including breast, bladder, and brain cancer (34) and is associated with tumor invasion $(10,35)$ and poorer clinical staging (36). HMGA1 overexpression induces inactivation of p53's apoptotic function to escape apoptosis in neoplastic transformation $(37,38)$ and drives stem cell properties in colon cancer cells (39). In our results, $H M G A 1$ expression level was an indicator of poor prognosis in CRC cases and an independent risk factor for lymph node metastasis. We consider that these results are due to the antiapoptotic function of HMGA1.

Intramucosal CRC generally does not metastasize to lymph nodes and is thus a good candidate for endoscopic local resection (40). By contrast, lymph node metastasis occurs in approximately $6-12 \%$ patients with submucosal invasive $\mathrm{CRC}$, which requires surgical resection, including lymph node dissection, for curative treatment (41-44). Despite the low possibility of lymph node metastasis in submucosal invasive CRC, surgical resection and removal of regional lymph nodes are considered the standard treatment for this disease (45). It is noteworthy that tumors with lymph node metastasis had significantly higher HMGAl expression levels in subgroup analysis for submucosal invasive CRC cases in our results. Perhaps submucosal invasive CRC cases without metastases, which might be cured by endoscopic local resection, could be extracted by $H M G A l$ expression level. Further studies using a larger number of cases are required.

In conclusion, our data strongly support the clinical significance of $H M G A l$ expression as a predictive indicator of lymph node metastasis in CRC cases, even in submucosal invasive CRC tumors.

\section{Acknowledgements}

The present study was supported in part by the following grants and foundations: CREST, Japan Science and Technology Agency (JST), and the Funding Program for Next Generation World-Leading Researchers (LS094). We would like to thank T. Shimooka, M. Kasagi and T. Kawano for their technical assistance.

\section{References}

1. Grade M, Hormann P, Becker S, et al: Gene expression profiling reveals a massive, aneuploidy-dependent transcriptional deregulation and distinct differences between lymph node-negative and lymph node-positive colon carcinomas. Cancer Res 67: 41-56, 2007.

2. Hao JM, Chen JZ, Sui HM, et al: A five-gene signature as a potential predictor of metastasis and survival in colorectal cancer. J Pathol 220: 475-489, 2010.

3. Meding S, Balluff B, Elsner M, et al: Tissue-based proteomics reveals FXYD3, S100A11 and GSTM3 as novel markers for regional lymph node metastasis in colon cancer. J Pathol 228: 459-470, 2012.

4. Gunderson LL, Jessup JM, Sargent DJ, Greene FL and Stewart AK: Revised TN categorization for colon cancer based on national survival outcomes data. J Clin Oncol 28: 264-271, 2010.

5. Weitz J, Koch M, Debus J, Hohler T, Galle PR and Buchler MW: Colorectal cancer. Lancet 365: 153-165, 2005.

6. Nishida K, Mine S, Utsunomiya T, et al: Global analysis of altered gene expressions during the process of esophageal squamous cel carcinogenesis in the rat: a study combined with a laser microdissection and a cDNA microarray. Cancer Res 65: 401-409, 2005.

7. Quackenbush J: Microarray data normalization and transformation. Nat Genet 32 (Suppl): 496-501, 2002.
8. Brazma A, Hingamp P, Quackenbush J, et al: Minimum information about a microarray experiment (MIAME)-toward standards for microarray data. Nat Genet 29: 365-371, 2001.

9. Niida A, Smith AD, Imoto S, Aburatani H, Zhang MQ and Akiyama T: Gene set-based module discovery in the breast cancer transcriptome. BMC Bioinformatics 10: 71, 2009.

10. Esposito F, Tornincasa M, Federico A, Chiappetta G, Pierantoni GM and Fusco A: High-mobility group A1 protein inhibits p53-mediated intrinsic apoptosis by interacting with Bcl-2 at mitochondria. Cell Death Dis 3: e383, 2012.

11. Kwon HC, Kim SH, Roh MS, et al: Gene expression profiling in lymph node-positive and lymph node-negative colorectal cancer. Dis Colon Rectum 47: 141-152, 2004.

12. Koehler A, Bataille F, Schmid C, et al: Gene expression profiling of colorectal cancer and metastases divides tumours according to their clinicopathological stage. J Pathol 204: 65-74, 2004.

13. Evan GI and Vousden KH: Proliferation, cell cycle and apoptosis in cancer. Nature 411: 342-348, 2001.

14. Thiery JP, Acloque H, Huang RY and Nieto MA: Epithelialmesenchymal transitions in development and disease. Cell 139: 871-890, 2009.

15. Acloque H, Adams MS, Fishwick K, Bronner-Fraser M and Nieto MA: Epithelial-mesenchymal transitions: the importance of changing cell state in development and disease. J Clin Invest 119: 1438-1449, 2009.

16. Reya T, Morrison SJ, Clarke MF and Weissman IL: Stem cells, cancer, and cancer stem cells. Nature 414: 105-111, 2001.

17. Ailles LE and Weissman IL: Cancer stem cells in solid tumors. Curr Opin Biotechnol 18: 460-466, 2007.

18. Grosschedl R, Giese K and Pagel J: HMG domain proteins: architectural elements in the assembly of nucleoprotein structures. Trends Genet 10: 94-100, 1994.

19. Reeves R and Nissen MS: The A.T-DNA-binding domain of mammalian high mobility group I chromosomal proteins. A novel peptide motif for recognizing DNA structure. J Biol Chem 265: 8573-8582, 1990.

20. Reeves R: Structure and function of the HMGI(Y) family of architectural transcription factors. Environ Health Perspect 108 (Suppl 5): 803-809, 2000.

21. Zhou X, Benson KF, Ashar HR and Chada K: Mutation responsible for the mouse pygmy phenotype in the developmentally regulated factor HMGI-C. Nature 376: 771-774, 1995.

22. Chiappetta G, Avantaggiato V, Visconti R, et al: High level expression of the HMGI (Y) gene during embryonic development. Oncogene 13: 2439-2446, 1996.

23. Chiappetta G, Bandiera A, Berlingieri MT, et al: The expression of the high mobility group HMGI (Y) proteins correlates with the malignant phenotype of human thyroid neoplasias. Oncogene 10: 1307-1314, 1995.

24. Chiappetta G, Tallini G, De Biasio MC, et al: Detection of high mobility group I HMGI(Y) protein in the diagnosis of thyroid tumors: HMGI(Y) expression represents a potential diagnostic indicator of carcinoma. Cancer Res 58: 4193-4198, 1998.

25. Fedele M, Bandiera A, Chiappetta G, et al: Human colorectal carcinomas express high levels of high mobility group HMGI(Y) proteins. Cancer Res 56: 1896-1901, 1996.

26. Abe N, Watanabe T, Sugiyama M, et al: Determination of high mobility group I(Y) expression level in colorectal neoplasias: a potential diagnostic marker. Cancer Res 59: 1169-1174, 1999.

27. Chiappetta G, Manfioletti G, Pentimalli F, et al: High mobility group HMGI(Y) protein expression in human colorectal hyperplastic and neoplastic diseases. Int J Cancer 91: 147-151, 2001.

28. Tamimi Y, van der Poel HG, Denyn MM, et al: Increased expression of high mobility group protein $\mathrm{I}(\mathrm{Y})$ in high grade prostatic cancer determined by in situ hybridization. Cancer Res 53: 5512-5516, 1993.

29. Abe N, Watanabe T, Izumisato Y, et al: Diagnostic significance of high mobility group $\mathrm{I}(\mathrm{Y})$ protein expression in intraductal papillary mucinous tumors of the pancreas. Pancreas 25: 198-204, 2002.

30. Bandiera A, Bonifacio D, Manfioletti G, et al: Expression of HMGI(Y) proteins in squamous intraepithelial and invasive lesions of the uterine cervix. Cancer Res 58: 426-431, 1998.

31. Masciullo V, Baldassarre G, Pentimalli F, et al: HMGA1 protein over-expression is a frequent feature of epithelial ovarian carcinomas. Carcinogenesis 24: 1191-1198, 2003.

32. Chiappetta G, Botti G, Monaco M, et al: HMGA1 protein overexpression in human breast carcinomas: correlation with ErbB2 expression. Clin Cancer Res 10: 7637-7644, 2004. 
33. Pomeroy SL, Tamayo P, Gaasenbeek M, et al: Prediction of central nervous system embryonal tumour outcome based on gene expression. Nature 415: 436-442, 2002.

34. Ben-Porath I, Thomson MW, Carey VJ, et al: An embryonic stem cell-like gene expression signature in poorly differentiated aggressive human tumors. Nat Genet 40: 499-507, 2008.

35. Mu G, Liu H, Zhou F, et al: Correlation of overexpression of HMGA1 and HMGA2 with poor tumor differentiation, invasion, and proliferation associated with let-7 down-regulation in retinoblastomas. Hum Pathol 41: 493-502, 2010.

36. Balcerczak M, Pasz-Walczak G, Balcerczak E, Wojtylak M, Kordek R and Mirowski M: HMGI(Y) gene expression in colorectal cancer: comparison with some histological typing, grading, and clinical staging. Pathol Res Pract 199: 641-646, 2003.

37. Pierantoni GM, Rinaldo C, Mottolese M, et al: High-mobility group A1 inhibits p53 by cytoplasmic relocalization of its proapoptotic activator HIPK2. J Clin Invest 117: 693-702, 2007.

38. Esposito F, Tornincasa M, Chieffi P, De Martino I, Pierantoni GM and Fusco A: High-mobility group A1 proteins regulate p53-mediated transcription of Bcl-2 gene. Cancer Res 70: 5379-5388, 2010.

39. Belton A, Gabrovsky A, Bae YK, et al: HMGA1 induces intestinal polyposis in transgenic mice and drives tumor progression and stem cell properties in colon cancer cells. PloS One 7 : e30034, 2012.
40. Morson BC, Whiteway JE, Jones EA, Macrae FA and Williams CB: Histopathology and prognosis of malignant colorectal polyps treated by endoscopic polypectomy. Gut 25 : 437-444, 1984

41. Kyzer S, Begin LR, Gordon PH and Mitmaker B: The care of patients with colorectal polyps that contain invasive adenocarcinoma. Endoscopic polypectomy or colectomy? Cancer 70: 2044-2050, 1992.

42. Minamoto T, Mai M, Ogino T, et al: Early invasive colorectal carcinomas metastatic to the lymph node with attention to their nonpolypoid development. Am J Gastroenterol 88: 1035-1039, 1993.

43. Nusko G, Mansmann U, Partzsch U, et al: Invasive carcinoma in colorectal adenomas: multivariate analysis of patient and adenoma characteristics. Endoscopy 29: 626-631, 1997.

44. Cooper HS: Surgical pathology of endoscopically removed malignant polyps of the colon and rectum. Am J Surg Pathol 7: 613-623, 1983.

45. Colacchio TA, Forde KA and Scantlebury VP: Endoscopic polypectomy: inadequate treatment for invasive colorectal carcinoma. Ann Surg 194: 704-707, 1981. 